\title{
UN DISEÑO DE ISIDRO GONZÁLEZ VELÁZQUEZ PARA LA CASA DEL LABRADOR DE ARANJUEZ EN UNA MESA DE ESCAYOLA INTARSIADA
}

\author{
ISMAel GutiÉRREZ PASTOR \\ Universidad Autónoma de Madrid
}

Una breve nota de identificación de modelos, descripción y estudio de un importante trabajo de escayola polícroma intarsiada, concebido como tapa de una mesa española de hacia 1830-1840.

Palabras clave: Escayola; Scagliola; Mobiliario; Familia Marzal; Casa del Labrador; Aranjuez; Arahal.

\section{A DESIGN BY ISIDRO GONZÁLEZ VELÁZQUEZ FOR THE CASA DEL LABRADOR DE ARANJUEZ IN AN INLAY PLASTERWORK TABLETOP}

A brief note on model identification, description and study of an important inlay polychrome plasterwork Spanish tabletop, c. $1830-1840$.

Key words: Plasterwork; Scagliola; Furniture; Marzal family; Casa del Labrador; Aranjuez; Arahal.

En 2010 el mercado de arte madrileño nos ha proporcionado la agradable sorpresa de una mesa con un magnífico tablero de escayola polícroma intarsiada, que merece ser rescatado de las espesas páginas del catálogo de la subasta y darlo a conocer como una de las piezas más curiosas de la escayola española del Neoclasicismo ${ }^{1}$. Dado a la venta por descendientes de uno de los más ilustres títulos de España, el mueble fue ofertado con la disyuntiva de que pudiera tratarse de una obra italiana o española del siglo XIX, y acompañado de una somera descripción que incluía su estructura, su decoración y su heráldica, además de un breve comentario sobre la escayola como técnica sustitutoria de los carísimos tableros de piedras duras que se habían realizado en los siglos del Barroco ${ }^{2}$.

El mueble en cuestión es una pequeña mesa de centro de 79 centímetros de altura rematada con una tapa de escayola en bastidor de madera que mide $83 \times 92$ centímetros (fig. 1). No se indica cual pueda ser la madera en la que está construida, aunque el color induce a pensar en una caoba rubia. De formas elegantes y ligeras, tiene patas en estípite unidas por una chambrana de dos secciones curvilíneas que se funden en un rectángulo central. El faldón del tablero, las caras de las patas y la chambrana se decoran con chapeados geométricos de marquetería, sacando el máximo efecto decorativo al veteado de las maderas claras. El borde de la tapa que hace las funciones de marco para la escayola también está decorado con una serie de círculos claros a modo de contario de perlas.

El tablero de escayola (fig. 2) presenta numerosos craquelados y algunas pérdidas en la última capa (coperta), además de una acentuada grieta, nada de lo cual afecta a la correcta apreciación del diseño geométrico empleado. Este modelo decorativo permite asegurar con toda evidencia que se trata de una obra española de la primera mitad del siglo XIX -hacia 1830-1840-, realizada con toda probabilidad en Madrid y en el círculo de los escayolistas reales, pues no es otro que el pavimento del Retrete de la Casa del Labrador de Aranjuez, diseñado a partir de junio de 1800 por el arquitecto Isidro González Velázquez, quien desde poco antes se había hecho cargo de las obras de ampliación de la Casa. Dicho pavimento, que combina los mármoles de colores con el mosaico de recreación romana en el medallón central y en los triángulos angulares del cuadrado central, fue colocado por Miguel Gutiérrez en 1803, integrando los mosaicos reali-

\footnotetext{
1 Trabajo realizado en el marco del Proyecto de Investigación HAR2009-11687: "Prestigio y poder. Los usos artísticos en España durante la Edad Moderna”, del Ministerio de Ciencia e Innovación.

2 Ansorena. Madrid. Subasta del 4, 5 y 6 de octubre de 2010, lote 1256, p. 333 y contraportada. Agradezco a Luis Pradillo Cendón sus informaciones sobre los resultados de la subasta y las imágenes que ilustran este texto.
} 


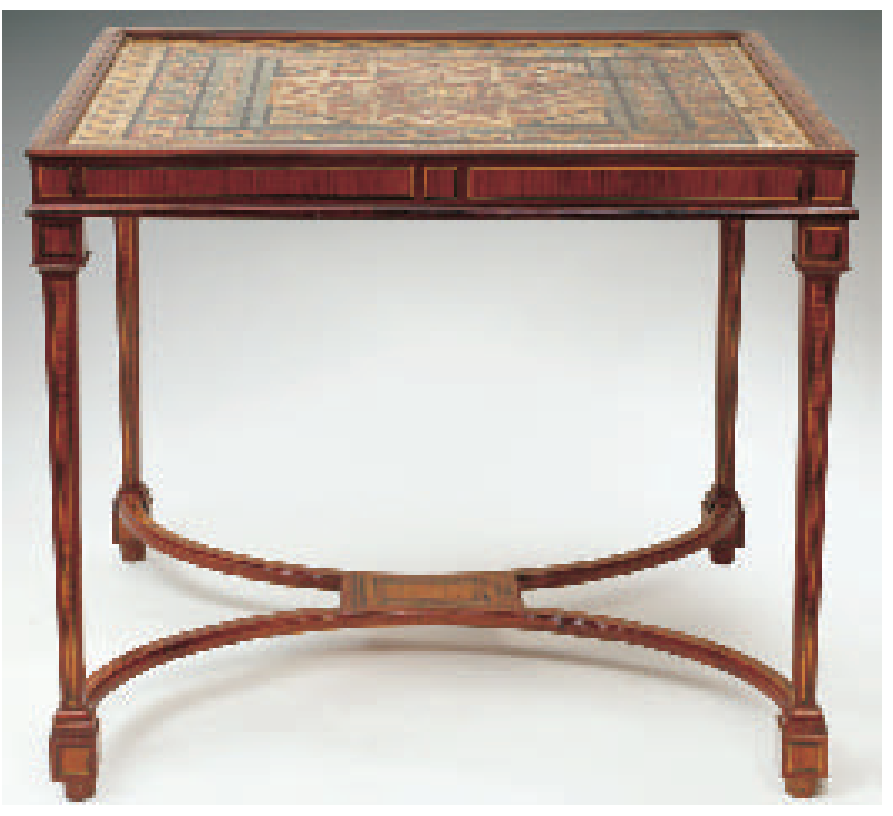

Fig. 1. Mesa de centro con tapa de escayola polícroma intarsiada. Madrid, hacia 1830-1840.

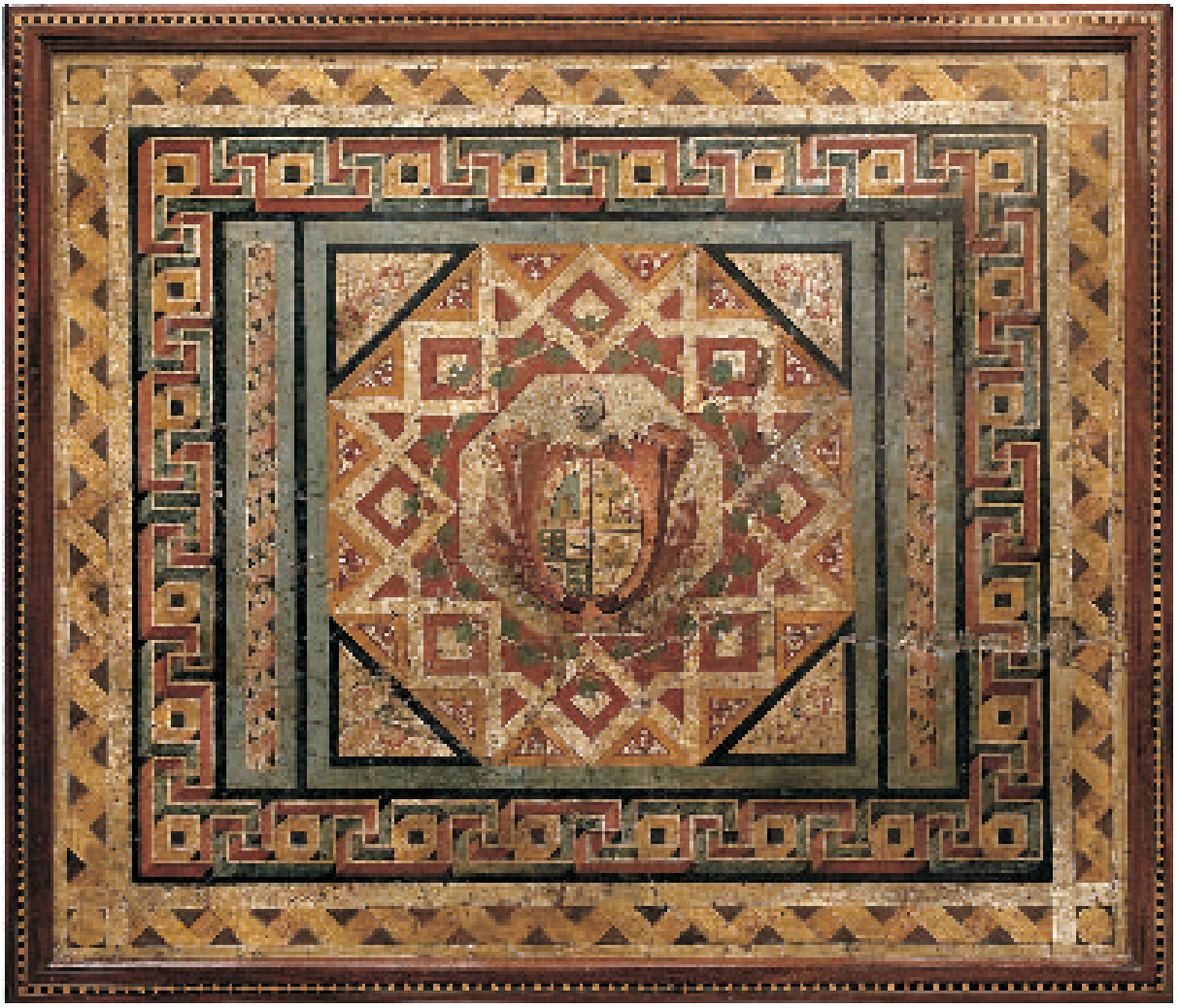

Fig. 2. Tapa de mesa de escayola polícroma intarsiada (según diseño de Isidro González Velázquez). Madrid, hacia 1830-1840.

Arch. esp. arte, LXXXIV, 335, JULIO-SEPTIEMBRE 2011, 271-275, ISSN: 0004-0428 
zados por Pascual Cortés entre febrero de 1801 y mayo de 1802. Simultáneamente y siguiendo el mismo diseño se realizó una alfombra de punto de tapicería en la Real Fábrica de Tapices de Santa Bárbara (Madrid, Patrimonio Nacional) ${ }^{3}$.

El pavimento de mármoles con mosaicos y la alfombra de punto de tapicería comparten el diseño que se atribuye a Isidro González Velázquez y que fue puesto a disposición de los artistas hacia 1801 para realizar una de las más lujosas y exquisitas decoraciones del reinado de Carlos IV. El tablero de escayola comparte el mismo diseño básico, si bien ha sido modificado para adaptarlo a las exigencias de un nuevo cliente, eliminando la traza de los dos cuadrados de ángulos girados que forman una estrella de ocho puntas y los mosaicos del mascarón central y de los cogollos florales de los rombos.

El vaciado de los motivos centrales fue necesario para crear un campo en el que colocar el escudo de armas del cliente, en el que residirá probablemente la clave de un encargo que por ahora resulta imposible de descifrar e, incluso, describir correctamente en heráldica como consecuencia de la pérdida de las tonalidades originales de los colores. Desde el punto de vista de la forma se trata de un escudo de hechura ovalada, cuartelado en cruz, que presenta en el 1 . $^{\text {er }}$ cuartel, una torre o castillo de oro sobre campo de azur y bordura de ocho panelas de gules sobre plata (o sobre oro); en el $2 .^{\circ}$, un árbol con un león pasante; en el 3..$^{\circ}$, cuartelado en cruz, con seis panelas de oro en campo de sinople puestas en dos palos, en los cuartes $1 .^{\circ}$ y $4 .^{\circ}$, y con un lobo pasante de sable en los cuarteles $2 .^{\circ}$ y $3 .^{\circ}$; finalmente, en el cuartel $4 .^{\circ}$, un árbol natural. La arquitectura del escudo se completa en la base con palmas y ramas de laurel, y en la cima con un yelmo de perfil con la visera abierta y levantada mostrando la rejilla que, a decir de Piferrer, es de acero bruñido y es propia de los hidalgos sin jurisdicción y de los nobles de tres líneas paternas y maternas ${ }^{4}$. Si las armas han sido bien entendidas y descritas las del primer cuartel podrían corresponder al apellido Ovejero y las del tercero al de Sarachaga, sin que la identificación garantice nada respecto al encargo de la obra en el siglo XIX. Por otro lado, y en relación con la procedencia inmediata de la mesa, los apellidos no se corresponden con los de la familia que puso la mesa en venta, ni sus ilustres apellidos están reflejados en las armas del escudo.

Aunque el aspecto de este escudo oval albergado por una arquitectura de perfiles rizados como de bronce o madera puede remontarse a las últimas décadas del siglo XVIII, sorprende de nuevo por su semejanza con otro diseño de Isidro González Velázquez que el arquitecto realizó en 1833 o poco después para contener las armas de los ocho apellidos de sus progenitores, así como sus propios honores y condecoraciones, recientemente reproducido con motivo de la exposición monográfica que se le ha dedicado ${ }^{5}$.

Es verdaderamente difícil desentrañar las claves del escudo que decora la tapa de la mesa para identificar a su primer propietario, del quien se puede afirmar tanta cercanía a los artistas de la corte y a sus creaciones como para hacerse servir una obra con exclusivos diseños creados para el rey. Por las circunstancias históricas del arranque del siglo XIX en España, con la Guerra de la Independencia seguida de otras varias inestabilidades políticas, así como por el estilo de la ebanistería de la

\footnotetext{
${ }^{3}$ Para todo lo relativo a la construcción y decoración del retrete de la Casa del Labrador, véase el artículo de JordÁn de URRIES y de LA Colina, Javier, "El Retrete de la Real Casa del Labrador", en Reales Sitios, n. 170 (2006), pp. 42-55. Id., La Real Casa del Labrador de Aranjuez, Madrid, 2009, p. 196.

${ }^{4}$ Piferrer, Francisco, Tratado de heráldica y blasón, ilustrado con láminas, por don José Asensio y Torres. Nueva Edición, revisada, corregida y aumentada por D. Francisco Piferrer, Madrid, 1853, p. 31, figura 90.

${ }_{5}$ Moleón Gavilanes, Pedro (ed.), Isidro Velázquez (1765-1840), arquitecto del Madrid fernandino, Catálogo de la exposición, Centro Cultural Conde Duque, Ayuntamiento de Madrid, 2009, pp. 104 y 570, documento 14. El escudo incluye las condecoraciones de la Orden Americana de Isabel la Católica, concedida por Fernando VII en 1833, y la de Carlos III, concedida por la reina M. ${ }^{a}$ Cristina de Borbón en el mismo año y que dio lugar a una indagación genealógica por parte del arquitecto (op. cit., 2009, p. 82).
} 
mesa es probable que ésta y su tablero fueran realizados hacia 1830-1840. Este tablero de escayola se presenta así como una obra surgida a partir de modelos más antiguos, lo cual no le resta mérito. Antes bien lo hace excepcional por su dependencia respecto a los modelos de González Velázquez, ejecutados por escayolistas españoles y sin referencia en otras escayolas europeas contemporáneas.

Cuando los estudios y el conocimiento de la escayola española se encuentran aún en fase muy incipiente, también es difícil proponer el nombre de un artista que pudiera haber realizado el tablero. Entre los escayolistas madrileños al servicio de las obras reales destacan los miembros de la familia Marzal ${ }^{6}$. Antonio Marzal, el menor (Valencia, 1778-Madrid o Aranjuez, 1804) fue el autor de las escayolas del Retrete de la Casa del Labrador de Aranjuez y falleció mientras se realizaban las escayolas de la Galería de las Estatuas del mismo palacete bajo la dirección del escultor José Ginés ${ }^{7}$. Su padre Antonio Marzal, el mayor (¿Valencia?, hacia 1750/1755-documentado en Madrid entre 1796-1807), también trabajaba en la Galería de Estatuas al morir su hijo y concluyó la obra bajo la supervisión del citado Ginés y de Isidro González Velázquez. Con anterioridad, en los últimos años del siglo XVIII había realizado por encargo del duque de Osuna la exedra arquitectónica que constituye el vistoso retablo mayor de escayola de la iglesia de Santa María Magdalena en Arahal (Sevilla) y unos escudos ducales, además de colocar la estatua de la santa en el retablo, por todo lo cual percibió desde 1800 hasta el finiquito de febrero de 1803 diversas cantidades de dinero: 56.630 reales por el retablo y 4.506 reales y 2 maravedís por "los escudos de armas de mi casa" y otros "gastos extraordinarios de la construcción de esta obra y colocación de la imagen de Santa María Magdalena"8. Después de la Guerra de la Inde-

${ }^{6}$ Un avance de la vida y obras de las tres generaciones de escayolistas de la familia Marzal puede verse en GuTIÉRREZ PASTOR, Ismael, "Piezas de mobiliario y decoración en escayola intarsiada, firmadas por Antonio y Vicente Marzal", en Archivo Español de Arte, LXXXII, n. ${ }^{\circ} 325$ (2009), pp. 63-73.

7 JoRdÁn DE URRiÉs y DE LA Colina, Javier, “Azara, coleccionista de antigüedades, y la Galería de estatuas de la Casa del Labrador de Aranjuez”, en Reales Sitios, n. ${ }^{\circ}$ 156, 2003.

8 AHN, Sección de la Nobleza, Toledo, Osuna CT 402, D.23: Orden del 6 de marzo de 1800 del duque de Osuna a Ildefonso Alberdi, encargado del arca de la tesorería provisional de la casa de la calle Leganitos (de Madrid), de pagar a Pascuala Galiana, mujer del escayolista Antonio Marzal, 600 reales a costa del retablo "que de mi orden está haciendo en mi villa del Arahal". En el reverso el recibí firmado de Pascuala Galiana. Incluye otros tres pagos de iguales cantidades, fechados el 4 de abril, el 5 de mayo y el 5 de junio de 1800. CT 402, D.24: "n. ${ }^{\circ} 10$. escayolista Marzal/6 mesadas a 600 reales.... 3.600 reales. El recibo del 25 de junio lo firma el mismo Marzal en Madrid por "seyssientos (sic) rs. v(ellón) a quenta del retablo de esqueyola (sic)..." del Arahal. Archivo de la Nobleza. Toledo. Osuna CT 617, D.12: Orden del duque, fechada el 4 de febrero de 1803, a Juan Pablo de Frutos, encargado de la tesorería de la casa de la calle Leganitos, de pagar a Antonio Marzal 3.638 rs y 2 mrs. por el "resto, cumplimiento y entero pago de los sesenta y un mil ciento treinta y ocho reales y $2 \mathrm{mr}$ que ha importado la obra hecha de mi orden en la Yglesia Parroquial de mi villa de Arahal, en esta forma: los cincuenta y seis mil seiscientos treinta y dos reales por la contrata en que se convino en construir el retablo mayor de la propia Yglesia, y los cuatro mil quinientos seis reales y dos mrs. restantes por el coste de los escudos de armas de mi casa que se han puesto en dicho retablo y gastos extraordinarios ocurridos en la construcción de esta obra y colocación de la imagen de santa María Magdalena, Patrona del Pueblo, según consta de las cuentas que ha presentado en mi contaduría, y en la que quedan recogidas. Que con este libramiento del cual se ha de tomar la razón y recibo a continuación del referido D. Antonio Marzal, mando se le haga buena la nominada cantidad. Madrid quatro de febrero de mil ochocientos y tres". En el reverso del documento consta el recibí de Marzal, redactado con valencianismos ("maravedisez que dise...").

El nombre de Marzal estaba asociado a la imagen de la Magdalena del retablo del Arahal, debido a que está firmada, aunque en el contexto sevillano se trataba de una escultor desconocido y de filiación clasicista y académica ( $c f r$. Recio Mir, Álvaro, "La escultura sevillana, la Academia de San Fernando y el ocaso de la escuela", en Academia, Boletín de la Real Academia de Bellas Artes de San Fernando, n. ${ }^{\circ}$ 104-105, 2007, pp. 135-156). Pero hay que señalar que, si bien la escultura resulta verdaderamente ajena al medio sevillano, los documentos sólo recogen pagos a Marzal por colocarla en el retablo, sin que se diga nada de su autoría, evidentemente avalada por la firma. Además de esta nueva faceta como escultor, los pagos del duque de Osuna por la obra del Arahal nos confirman a un Marzal arquitecto de retablos en escayola (stucco marmo) al servicio de los ideales de la Academia y de la desaparición de los retablos 
pendencia, las necesidades del servicio real en el campo de las escayolas: nuevas obras, conservación, limpieza y mantenimiento de las escayolas antiguas quedó al cargo de Paolo Caprani (Laíno, Como, Italia, 1752-Madrid, 1818), Vicente Marzal (Valencia, hacia 1788/1789-Madrid, 1858) y Cayetano Orsolino (Ramponio, Lombardía, 1772-Aranjuez, 1846). Después de haberse especializado en la escayola marmorizada de carácter arquitectónico, Caprani falleció pronto. Vicente Marzal parece haber sido el más capaz. Orsolino fue nombrado conservador de las escayolas del palacio de San Ildefonso. Se conocen buenas tapas para veladores de Vicente Marzal, como la que realizó para el cuarto de la reina María Josefa de Sajonia (1829) ${ }^{9}$, cuyos modelos se remontan tres décadas atrás hasta enlazar con los zócalos de la galería de estatuas de la Casa del Labrador -donde había colaborado con su hermano y su padre- y son completamente distintos al de la tapa que analizamos. Se trata de otro caso de reutilización de modelos de la Casa del Labrador, lo cual le señala como posible autor del tablero de nuestra mesa de centro.

La escayola comenzó a cultivarse en la Corte de Madrid a mediados del siglo XVIII como un sistema de decoración en relación con la Corte y con las grandes casas nobiliarias BenaventeOsuna y Alba, que emplearon la escayola intarsiada en la decoración de La Alameda de Osuna y en el palacete de La Moncloa respectivamente. En el siglo XIX continuaron sus usos, pero diversas circunstancias hicieron que la escayola decayera. En 1824, al concluir el Trienio Liberal, Fernando VII sometió a varios escayolistas a procesos de depuración administrativa. Una década después, la reina María Cristina de Borbón, en funciones de regente en la minoría de edad de la reina Isabel II, procedió a depurar nuevamente a los afectos al carlismo, entre los que se encontró Vicente Marzal y su hijo, Mariano Marzal Serrano ${ }^{10}$, y a recortar drásticamente la plantilla de los empleados de Palacio mediante supresiones de empleos y jubilaciones, que a partir de 1834 provocaron la falta de trabajo para muchos de ellos y que alguno de ellos reclamara obras de protección real porque la escayola se había convertido en una técnica cara y de lujo que pocos podían afrontar. Sin duda alguna estas circunstancias obligarían a los escayolistas a abrir su oferta a otros sectores de la sociedad y que la incipiente burguesía, acaso ennoblecida, entrara a demandar algunas obras de escayola. En este contexto ha de situarse la realización de esta mesa con su tapa de escayola polícroma intarsiada que rescata un prestigioso modelo real varias décadas después de que se hubiera ejecutado como pavimento en la Casa del Labrador de Aranjuez.

de madera, recuperando un aspecto que había cultivado en Valencia antes de trasladarse a Madrid (cfr. BERCHEZ, Joaquín, Arquitectura y academicismo en el siglo XVIII valenciano, Valencia, 1985, pp. 259-260 y nota 135, lám. 92). Sin embargo, no hay que descartar que Marzal estuviera ejecutando obras proyectadas por otros artistas del círculo del duque de Osuna o de su mujer, la duquesa de Benavente.

9 AGP (Archivo General de Palacio Real), Madrid, Sección Administrativa General, legado 5.233, exp. 13: cuenta del 19 de febrero de 1829. Por la descripción ("tiene de diámetro tres pies menos cuatro dedos, con un grupo de figuras en el centro y varios adornos alrededor, todo de embutidos") podría tratarse del velador de tapa circular que Patrimonio Nacional tiene en el palacio de la Almudaina, en Palma de Mallorca. Inventario: número 10030048P. Véase L. Feduchi, Colecciones Reales de España. El mueble, Madrid, 1965, p. 460, lámina 384.

${ }^{10}$ Moral Roncal, Antonio Manuel, "Carlismo y mecenazgo regio: las depuraciones de 1834-1835", en Boletín del Museo e Instituto Camón Aznar, LXXXI, 2000, pp. 127-151, con referencia a los Marzal en las pp. 138-139. 